\title{
EFFECTS OF CORE EMPLOYEES ON ORGANIZATIONAL CAPABILITIES AND FIRM PERFORMANCE
}

\author{
Oya ERDIL \\ Hakan KITAPCI \\ Beyza TIMURLENK \\ Gebze Institute of Technology, TURKEY
}

\begin{abstract}
This study explores the impact of core employee characteristics on organizational capabilities and firm performance. The resource based view asserts that organizations with valuable and inimitable resources will attain competitive advantage and organizational performance. The effects of valuable and unique core employees on organizational capabilities namely managerial, technical capabilities and output based capabilities and overall firm performance are analyzed in this study. We used a statistical methodology to test the relationships hypothesized in the research model. The results indicated a higher organizational capability and organizational performance for firms using the most valuable core employees.
\end{abstract}

Keywords: Core employees, Value, Uniqueness, Organizational capabilities, Firm performance.

\section{Theory and Hypotheses Development}

Resource-based theory, one of the most widely accepted theories of strategic management and originally formalized in 1991, views the firm as a bundle of resources and emphasizes that competing firms possess heterogeneous resource bases (Song et al., 2007). It explains the importance of developing resources and capabilities which are valuable, rare, inimitable and non-substitutable. The attainment of such advantages will enable the firm to improve its short-term and long-term performance (Newbert, 2008). Although it is necessary for a firm to possess valuable and inimitable resources and capabilities, firms seeking a competitive advantage must also demonstrate the ability to alter them for full realization of their potential (Newbert, 2007). Therefore, resources are the substance of strategy because competitive advantage (CA) is a match between the organization's resources and capabilities and the environmental opportunities and risks it faces, and the objectives of the organization. They are considered to be the very essence of CA because a firm's ability to gain and preserve its profitability depends on its ability to defend its advantageous position that is related to its resources and capabilities (Carmeli, 2004).

Whereas resources usually are considered to be finite in supply and to diminish in value when shared with other parties, capabilities refer to the dynamic, non-finite, firm-specific and path dependent processes that are not obtainable in the market place, are difficult to copy, and are accumulated through long-term, continuous learning (Spanos and Prastacos, 2004). Hence, capabilities are seen as the ability to coordinate and deploy resources in order to achieve the firm's goals (McKelvie, Davidsson, 2009). This implies that while resources seldom lead to performance differences on their own, the application of resources (i.e. capabilities) is what causes performance differences. Capabilities are defined as complex bundles of skills and accumulated knowledge that enable firms to coordinate activities and make use of their assets (Day, 1994). Every business develops its own configuration of capabilities that is rooted in the realities of its competitive market, past commitments and anticipated requirements (Song and Benedetto, 2007). The resource-based view (RBV) of the firm explains how firms allocate their scarce resources to obtain and exploit competitive capabilities. Therefore, the firm that has the resources and abilities to put its capabilities to best use, and that invests in capabilities that complement the existing capability structure will be able to exploit its distinctive competences (Song and Benedetto, 2007).

Capabilities may enhance competitive advantage by preventing imitation. Organizational capabilities 
may be defined as the ability of a company to create and develop differentiating features and advantageous internal processes and structures (Lado and Wilson, 1994). To create economic value, sustain competitive advantage and achieve superior organizational performance, an organization requires a wide range of capabilities. Organizational capabilities can be grouped according to their orientation. One classification of organizational capabilities is given as a set of dynamic capabilities, namely idea generation capabilities, market disruptiveness capabilities, new product development and new process development capabilities (McKelvie, Davidsson, 2009). In another study, Song and his colleagues (2007) focus on four capabilities; technology, IT, market-linking and marketing capabilities. Another classification of organizational capabilities focuses on managerial capabilities, technical capabilities and output-based capabilities (Turner and Crawford, 1994). In our study we operational this classification of capabilities which are given as managerial, technical and output based capabilities in order to test the hypotheses given in the research model investigating relationships between core employee characteristics, organizational capabilities and firm performance.

\section{Human Capability and Key Employees}

Development of human capital consistently enables superior performance (Gimeno et.al., 1997). Firms which attract highly educated and/or highly skilled workers, provide skill-development and cross-training develop difficult to trade and imitate, scarce and appropriable specialized human capital assets (Amit and Shoemaker, 1993). Attracting and retaining high-quality personnel is considered a critical innovation strategy, particularly for high-tech firms (Branzei and Vertinsky, 2006).

The HR component of organizational capabilities usually includes the knowledge, expertise, talents, creativity, and skills of a firm's personnel. The RBV asserts that the unique skills and experiences of internally-based personnel can give the firm a competitive advantage. This can be achieved by recruiting, and maintaining a well-trained labor force and managers whose knowledge, skills and abilities serve as a source of innovation (Zahra and Nielsen, 2002).

Employee human capital of the firm refers to the knowledge, skills and abilities that employees possess and use in their work. Studies of employee human capital have found direct positive effects on firm performance (McKelvie and Davidsson, 2009). Emprical studies have examined the role of employees as an enabling factor which allows the firm to acquire and apply new knowledge (Celuch et al., 2002) to allow other resources and capabilities to be developed fully (Ranft and Lord, 2002). Therefore, firms should base employment sourcing decisions on the degree to which skills contribute to the core capabilities of the firm. The resource-based perspective encourages a shift toward the employee skills and their relative contribution to value creation. This theory suggests that core employee skills should be developed and maintained internally specifically based on value-creating potential and uniqueness of employees (Lepak and Snell, 1999).

\section{The Value of Human Capital}

If a resource or capability yields the potential to enable a firm to reduce costs and/or respond to environmental opportunities and threats, it is valuable, and to the extent that a firm is able to effectively deploy such a resource it will attain competitive advantage (Barney, 1991). Employee skills as core assets are vital and often require continual internal development. A core employee can be considered to be the worker who is specifying the core activity in the firm and performs the organization's base operations related to making the product or providing the service (Lopez-Cabrales et al., 2006).These skills must somehow contribute toward consumer-based perceptions of value. Thus employees can add value if they can help firms offer lower costs or provide increased benefits to consumers (Lepak and Snell, 1999). Irwin et al., (1998) measure value as the degree to which the resource in question can increase customers, occupancy, and reputation and then measure the dependent variable. As such, in this study it is formally proposed that valuable core employees is positively related to firm performance.

\section{Uniqueness of Core Employees}

Employee uniqueness is defined as the extent to which a particular form of human capital is idiosyncratic to a particular firm. Human capital uniqueness can be measured with an index that includes the difficulty of replacing the employees and the difficulty that competitors would have in duplicating 
them (Lopez-Cabrales et al., 2006). Specifically, such practices as team-based production, and unique operational procedures that lead to enhanced social complexity, and the development of tacit knowledge will enhance the uniqueness of a firm's human capital. Because these skills often involve idiosyncratic learning processes, firms are not likely to find these skills in the open labor market (Lepak and Snell,1999). In this study it is proposed that unique employees are positively related to firm capabilities and firm performance.

\section{Organizational Capabilities}

A great deal of theoretical work began to emerge regarding the types of processes to which resources must be subjected in order to exploit their latent value such as core capabilities, competences and organizational capabilities (Newbert, 2007). In his study, Barney (1991) argued that in addition to simply possessing valuable, rare, inimitable and unique resources, a firm also needed to be organized in such a manner that it could exploit the full potential of those resources if it was to attain a competitive advantage. He further suggested that the implementation skills that could ensure proper resource exploitation included such organizational components as structure, control systems and compensation policies. While resources are no doubt important to a firm's competitive advantage, firms need to also possess and be able to replicate routines to gain competitive advantage and maintain organizational performance. In this study, organizational capabilities are classified into three groups according to their orientations based on the research of various authors: managerial capabilities, technical capabilities and output-based capabilities (Lopez-Cabrales et al., 2006, Lado and Wilson, 1994).

\section{Managerial Capabilities}

Managerial capabilities were defined as possessing the ability to create a strategic vision and identity for the company, communicate these throughout the organization, and encourage the workforce to achieve them (Lopez-Cabrales et al., 2006). Recent theoretical developments suggest that organizational capabilities evolve over time, and several organizational and environmental levers contribute to their founding, development, maturation and alteration. Managerial decisions are acknowledged as some of the most critical antecedents of capability transformation (Helfat and Peteraf, 2003). Suitable strategic choices help firms overcome the constraints of their existing resource endowments by guiding the development of extant skills and by facilitating the emergence of new capabilities (Branzei and Vertinsky, 2006). The literature suggests four main managerial capabilities: reinforcement of the organizational culture, strategic vision, obtaining employee potential, and flexible design (Lado and Wilson, 1994). In this study, we use this classification of managerial capabilities with the above stated four dimensions.

\section{Technical Capabilities}

Technical capabilities concern the manufacturing processes, technology, new product development, production facilities in the industry. These skills are contained within the organization and are activated by market, competitor, and external challenges (Song et al., 2007). These are organizational capabilities that contribute at the time of turning inputs into outputs. They refer to the technological aspects of the creation, production, and development of products and services. The technical capability for innovation is key to carrying out new combinations of resources, methods, systems and processes to generate new products and services (Lopez-Cabrales et al., 2006). There is no shortage of literature that illustrates the importance of knowledge, and innovation for superior firm performance (Cho and Pucik, 2005). The literature also suggests that CEs with firm specific knowledge and skills contribute to technical innovation because they possess the proper set of behaviors for making improvements in current operations (Lopez-Cabrales et al., 2006).

\section{Output-based Capabilities}

A subset of capabilities in any firm involves creating physical or intangible assets that provide value to the customer. These capabilities are called output-based (Lado and Wilson, 2006). In this study, we used three organizational capabilities from the customer viewpoint: quality orientation, customer loyalty, and product diversity based upon the study of Lopez-Cabrales et al.,(2006). A good company reputation may arise from a firm's dedication to creating and delivering products or services of superior quality that may yield competitice advantage in the market. Repeated findings on quality 
either measured by customer satisfaction or perceived quality, provide a growing body of evidence that the relationship between quality and firm performance is positive (Cho and Pucik, 2005). Firms also promote close relationships with customers that will in turn generate high sales and returns relative to competitors. Product diversity enables the firms to anticipate customers' needs. CEs play a critical role in developing output-based capabilities.

\section{Firm Performance}

Conceptualization and measurement of organizational performance is a thorny topic in strategy research and many different variables have been used. Organizational constructs include such variables as competitive advantage, market share, profit, costs, sales revenue and customer satisfaction. Authors classify these into two wide categories: objective measures (such as return on assets) and perceptual measures (comparisons of self with competitors). When conducting surveys managers have been more open to offering their general views than to offering precise quantitative data (Montes et al., 2005). We tested the model using a perceptual measure of financial and operative performance in which each respondent rated his or her organization's performance relative to that of other firms in the sector.

\section{Research Methodology Data Collection and Sample}

The study employs a questionnaire survey approach to collect data for testing the validity of the model and research hypotheses. Variables in the questionnaire include key employee capability, managerial capabilities, technical capabilities, outcome based capabilities and firm performance. All dependent and independent variables are measured by seven-point Likert-type responses ranging from "strongly disagree" to "strongly agree". The population for the study is the firms located in Gebze and Tuzla industrial zone. A list of randomly selected 300 firms has been taken as the sample for the survey. The final sample included 104 firms (34\% response rate).

As for the characteristics of the final sample, the majority of the respondents were male $(54,8 \%)$, and mean respondent age was 33 years old, and $64,4 \%$ of the respondents were at least college graduates.

\section{Figure 1: The proposed model of the study}

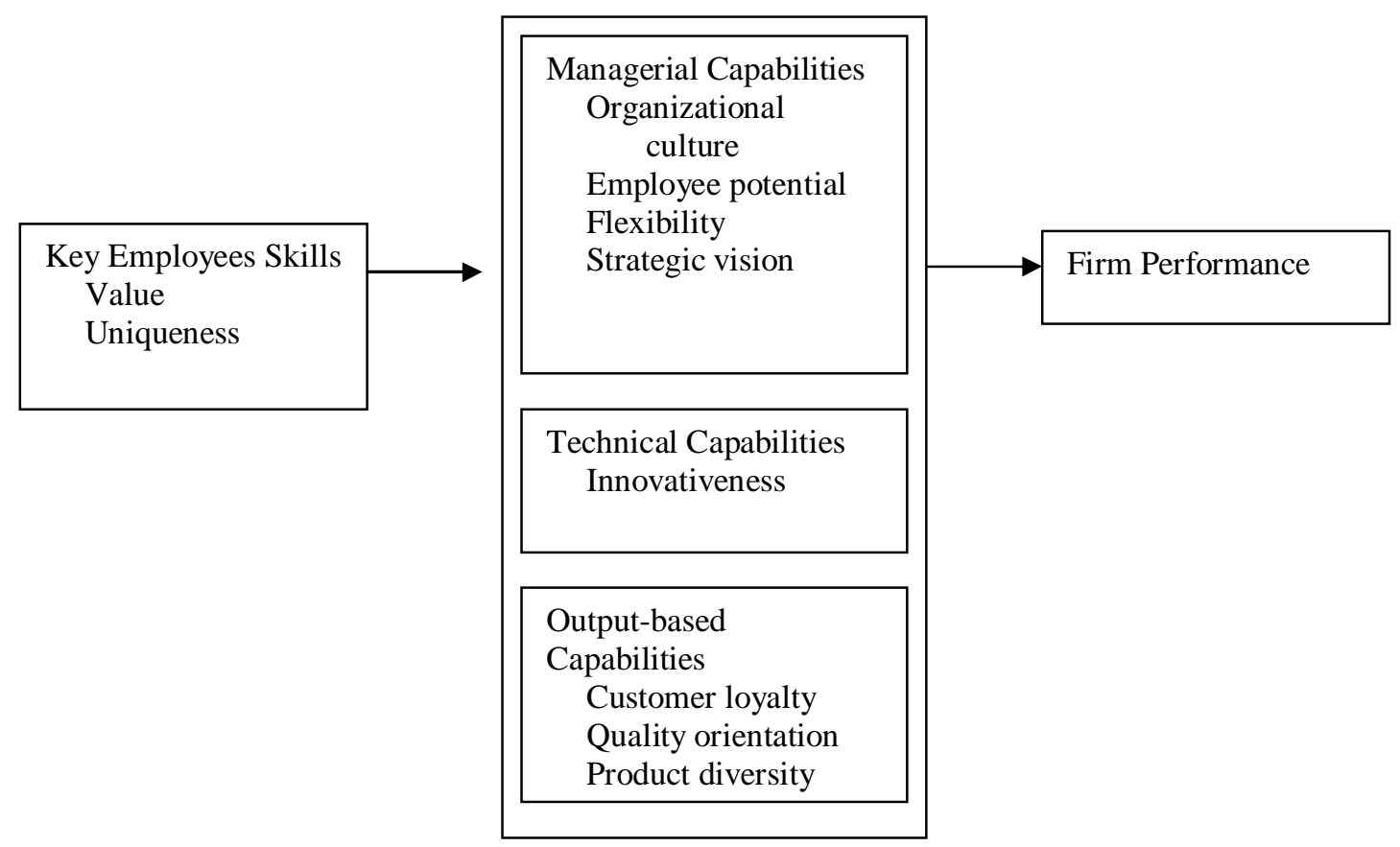




\section{Measures}

Following the distinction of previous researchers (e.g. Barney, 1991) the present study adopts two dimensions of key employee characteristics including value and uniqueness. A 12-item scale to measure uniqueness and another 13-item scale to measure value based on the work of LopezCabrales et al., (2006) is used in the empirical research. Drawing upon previous researches (e.g. Newbert, 2005; McKelvie and Davidsson, 2009) this study adopts three aspects of organizational capability including managerial capabilities, technical capabilities and outcome-based capabilities. The management capability construct consists of four dimensions including organizational culture, employee potential, flexibility and strategic vision measured with $6,6,5$ and 5 questions respectively. Technical capability is limited to innovativeness and measured with a four-item scale. Outputbased capabilities construct consists of 3 dimensions, namely customer loyalty, quality orientation and product diversity measured with 5 questions each. Lastly, firm performance construct consists of 7 items to indicate the extent of perceived overall firm performance compared to that of competitors. The scale is adopted from the research study conducted by Choi and Lee(2003).

\section{Measurement Validation}

Before testing the hypotheses, we performed principal factor analysis with varimax rotation. Core employee characteristics were loaded into two factors with $52 \%$ of variance explained. We entered 22 managerial capabilities items into a separate exploratory factor analysis. The resultant factor structure clearly reflected four managerial capabilities with $70 \%$ of variance explained. The second component of capabilities namely technical capabilities was loaded into one factor. The final capability component, output-based capabilities, was measured by 14 items producing three factors as expected and $64 \%$ of the variance is explained by the three factors. Lastly, seven items measuring firm performance was loaded into one factor explaining $54 \%$ of the variance.

The internal consistency measures (Cronbach's alpha) were obtained in order to assess the reliability of the measurement instruments. The alpha reliabilities of the factors were $0.89,0.85,0.70,0.72$, $0.69,0.84,0.81,0.70,0.83$, and 0.83 respectively. Construct reliabilities for all measures exceeded the critical value of 0,70 suggesting that the measures are highly reliable except flexibility dimension with an alpha value of $39.96 \%$ which is far below the critical value of $70 \%$ and thus flexibility is excluded from the proposed model. Examination of the patterns of item-item correlations and regression models indicate conclusions for the hypotheses in the study.

\section{Correlation Analysis}

We further studied strength of the relationships between the variables included in the research model. Results of the correlation analysis indicate that value of core employees and uniqueness of core employees are correlated with all dimensions of organizational capabilities and with firm performance with the exception of product diversity dimension at 0.05 significance level. Organizational culture is correlated with strategic vision, use of employee potential, innovation, customer loyalty and quality orientation. Strategic vision is correlated with all of the variables. Obtaining employee potential is correlated with all other variables with the exception of product diversity at 0.01 and 0.05 significance levels.

\section{Regression Analyses Results}

We performed a series of regression analysis to explore the proposed relationships in our hypotheses. In regression analyses we modeled five separate regression equations (Model 1, 2, 3, 4 and 5). In all four models within the first group of analyses, value and uniqueness constitute independent variables. On the other hand dependent variables are Managerial Capabilities in Model 1, Technical Capabilities in model 2, Output-based Capabilities in model 3 and Firm Performance in model 4 and 5. All regression models are found to be statistically significant with $\left(\mathrm{F}_{\text {Model- } 1}=19,769, \quad \mathrm{p}<0.01 ; \mathrm{F}_{\text {Model }}\right.$

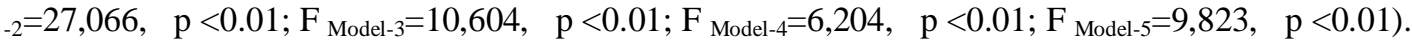
Results of the regression analyses are displayed in Table 1. 
Table 1. Regression Analysis

\begin{tabular}{|c|c|c|c|c|c|c|c|c|c|c|}
\hline \multirow[b]{2}{*}{ Independents } & \multicolumn{2}{|c|}{$\begin{array}{c}\text { Model 1 } \\
\text { Managerial } \\
\text { Capabilities }\end{array}$} & \multicolumn{2}{|c|}{$\begin{array}{c}\text { Model 2 } \\
\text { Technical } \\
\text { Capabilities }\end{array}$} & \multicolumn{2}{|c|}{$\begin{array}{c}\text { Model 3 } \\
\text { Output-based } \\
\text { Capabilities }\end{array}$} & \multicolumn{2}{|c|}{$\begin{array}{c}\text { Model } 4 \\
\text { Firm } \\
\text { Performance }\end{array}$} & \multicolumn{2}{|c|}{$\begin{array}{c}\text { Model 5 } \\
\text { Firm } \\
\text { Performance }\end{array}$} \\
\hline & $\mathrm{b}$ & Sig. & $\mathrm{b}$ & Sig. & $\mathrm{b}$ & Sig. & $\mathrm{b}$ & Sig. & $\mathrm{b}$ & Sig. \\
\hline Value & 0,476 & $0,000 *$ & 0,519 & $0,000^{*}$ & 0,380 & $0,000^{*}$ & 0,216 & $\mathbf{0 , 0 3 5} * *$ & - & - \\
\hline Uniqueness & 0,116 & 0,207 & 0,147 & 0,093 & 0,079 & 0,420 & 0,182 & 0,076 & - & - \\
\hline $\begin{array}{l}\text { Customer } \\
\text { loyalty }\end{array}$ & - & - & - & - & - & - & - & - & 0,213 & $\begin{array}{c}\mathbf{0 , 0 3 7} * \\
*\end{array}$ \\
\hline $\begin{array}{l}\text { Quality } \\
\text { orientation }\end{array}$ & - & - & - & - & - & - & - & - & $\begin{array}{c}- \\
0,293\end{array}$ & 0,002* \\
\hline $\begin{array}{l}\text { Product } \\
\text { diversity }\end{array}$ & - & - & - & - & - & - & - & - & 0,266 & $\begin{array}{c}\mathbf{0 , 0 1 1}^{*} \\
*\end{array}$ \\
\hline $\begin{array}{r}F \\
R^{2} \\
\text { Sig. }\end{array}$ & \multicolumn{2}{|c|}{$\begin{array}{c}19,769 \\
0,281 \\
0,000 *\end{array}$} & \multicolumn{2}{|c|}{$\begin{array}{c}27,066 \\
0,349 \\
0,000 *\end{array}$} & \multicolumn{2}{|c|}{$\begin{array}{c}10,604 \\
0,174 \\
0,000 *\end{array}$} & \multicolumn{2}{|c|}{$\begin{array}{c}6.204 \\
0,109 \\
0.003 *\end{array}$} & \multicolumn{2}{|c|}{$\begin{array}{c}9,823 \\
0,228 \\
0,000 *\end{array}$} \\
\hline
\end{tabular}

*Significant at the level of $P<0,01$

$* *$ Significant at the level of $P<0,05$

In the first four models, core employee value is found to be significantly and positively associated with managerial capabilities, technical capabilities, output-based capabilities and firm performance (Model 1, b=0,476, $\mathrm{p}<0.01$; Model 2, b=0,519, $\mathrm{p}<0.01$; Model 3, b=0,380, p <0.01; Model 4, $\mathrm{b}=0,216, \mathrm{p}<0.05)$.

In model 5, customer loyalty, quality orientation and product diversity are considered as independent variables. Dependent variable is firm performance. Customer loyalty and product diversity are found to be positively associated with firm performance ( $b=0,213, p<0.05 ; b=0,266, p<0.05)$. Whereas quality orientation is found to be negatively associated with firm performance $(b=-0,293, p<0.01)$.

\section{Conclusions and Discussion}

Human capital within an organization includes knowledge, skills, abilities and perceptions of employees which maintains firm competitiveness and performance. This research study has revealed a link between core employee characteristics, organizational capabilities and firm performance. The results of this study imply that value of core employees seem to be the key to organizational capabilities and firm performance. This suggests that the organizations should focus on valuable employees in achieving business performance outcomes.

Lopez et al., (2006) found out that core employees value and uniqueness has a significant effect on organizational capabilities. Similarly, Choe and colleagues (2006) identified a positive relationship between employee skills, organizational structure and firm performance. In their research, Gatignon and Xuereb (1997) found the impact of human skills on firm performance. Therefore, in our study we tested the hypotheses stating that valuable and unique core employees will increase firm performance.

Regression analyses held in order to test the effect of valuable core employees on firm performance revealed a significant relationship whereas no significant relationship exists for the uniqueness. This result is inconsistent with the previous research. This might be due to the inclusion of the value and uniqueness characteristics as separate dimensions into the model rather than taking the two factors as one single dimension as is the case in some research models in the literature.

As with the organizational capabilities, the results of the research indicate a positive significant relationship between value of core employees and managerial capabilities. Furthermore, valuable core employees have been found to be significantly related to technical capabilities and output based capabilities with sub dimensions of quality orientation, customer loyalty and product diversity.

Resource based view deals with the assumption that organizational resources and competencies have a direct impact on firm performance (i.e., Baker and Sinkula, 2005). In this research study, organiza- 
tional capabilities have been investigated under three sub-dimensions: managerial, technical and output-based capabilities. Research results indicate that output based capabilities with its three dimensions of customer loyalty, quality orientation, and product variety have a positive impact on firm performance which is consistent with previous research (i.e., Morgan et al., 2009).

Inconsistent with previous research (i.e., Hartog and Verburg, 2004), our findings indicate that there exists no significant relationship between sub-dimensions of managerial capabilities namely organizational culture, obtaining employee potential and flexibility and firm performance. Another surprising finding is that technical capabilities taken as innovativeness also was not found to be related to firm performance.

This result, inconsistent with the previous research might stem from the use of firm performance as dependent variable. Although most of the academics and managers consider firm performance as a basic factor for firm success, it does not always seem to be true for the RBV. Companies operating in a variety of businesses might be successful in gaining competitiveness in some areas still becoming not that much successful in some other areas. Therefore, measuring overall firm performance might reveal surprising conclusions in analyzing the relationships between various business processes and firm specific resources. Furthermore, the firm still having resources and capabilities for attaining competitive advantage might not become in a position to make full use of these resources. For example, because firms can have competitive advantages in some business activities and competitive disadvantages in others, examining the relationship between resources associated with different processes within a firm and a firm's overall performance can lead misleading conclusions with regard to resource-based theory (Ray et al., 2004). Aggregating the outcomes of numerous processes which have the effect of increasing or decreasing a firm's overall performance, can make it very difficult to examine the kinds of resources and capabilities that can generate the competitive advantages and organizational performance.

Another reason for inconsistency might be the time period in which the research was conducted. During the last financial crises period, firms probably have been able to get use of human potential which have been more available in labor market than before. Hence, these effects might have been influential in explaining the stronger impact of value of core employees rather than uniqueness on organizational capabilities and firm performance.

\section{Limitations and Future Research}

This study has produced several provocative and surprising findings. More in-depth future research is needed to explore the underlying reasons for the relationships depicted in the data. This study has its own limitations. First, we have only examined three organizational capabilities such as managerial and output-based capabilities. Future research should explore the effect of other capabilities on overall firm performance and how capability types moderate the core employee characteristicsperformance relationship.

Second, this study suffers from the common limitations inherent in survey-based research. The study relies on self-reported information of the managers on the sample which could be increased in number.

From the perspective of managers, research on understanding why some capabilities or practices are able to generate competitive advantage and overall performance while others cannot is likely to be more helpful than research that examines just the relationship between resources and firm performance at a more aggregate level. In addition, to realize the full competitive potential of its resources and capabilities, a firm must organize its business processes efficiently. 


\section{REFERENCES}

Amit, R., Shoemaker, P.J.H., (1993), Strategic assets and organizational rent, Strategic Management Journal, 14,1: pp.33-46.

Baker, W.W., Sinkula, J.M., (1999), The synergistic effect of market orientation and learning orientation on organizational performance, Journal of the Academy of Marketing Science, 27, 4: pp.411427.

Barney, J.B., (1991), Firm resources and sustained competitive advantage, Journal of Management, 17(1): pp.99-120.

Branzei, O., Vertinsky, I., (2006), Strategic pathways to product innovation capabilities in SMEs, J of Business Venturing, 21, 1: pp.75-105.

Carmeli, A. ,(2004), Assessing core intangible resources, European Management Journal, 22,1; pp.110-122.

Celuch, K.G., Kasouf, C.J., Peruvemba, V., (2002), The effects of perceived market and learning orientation on assessed organizational capabilities, Industrial Marketing Management, 31, pp.545554.

Cho, H., Pucik, V., (2005), Relationship between innovativeness, quality, growth, profitability, and market value, Strategic Management Journal, 26: pp.555-575.

Choe, S., Woods, R., Erdem, M., (2006), Measuring the impact of HRM practices on hospitality firms' performances, Hospitality Management, 25: pp.262-277.

Coff, R.W., (1999), When competitive advantage doesn't lead to performance: The resource-based view and stakeholder bargaining power, Organization Science, 10(2): pp.119-133.

Day, G.S., (1994), The capabilities of the market driven organizations, Journal of Marketing, 58,1: pp.37-52.

Gatignon, H., Xuereb, J.M., (1997), Strategic orientation of the firm's new product performance, Journal of Marketing Research, 34,1: p.77.

Gimeno, J., Folta, T.B., Cooper, A.C., Woo, C.Y., (1997), Survival of the Fittest? Entrepreneurial human capital and the persistence of underperforming firms, Adm. Science Quarterly, 42, 4: pp.750783.

Hartog, D.N. Den and Robert M. Verburg, (2004), High performance work systems, organizational culture and firm effectiveness, Human Resource Management Journal, 14, 1, p.55.

Helfat, C.E., Peteraf, M.A., (2003), The dynamic resource-based view:Capability life-cycles, Strategic Management Journal, 24; pp.997-1010.

Irwin, J.G., Hoffman, J.J., Lamont, B.T., (1998), The effect of the acquisition of technological innovations on organizational performance: A resource-based view, J of Engineering and Technology Management, 15,1: pp.25-54.

Lado, A.Wilson, M., (1994), Human resource systems and sustained competitive advantage: A competency based perspective, Academy of Management Review, 19: pp.699-727.

Lepak, D.P., Snell, S.A., (1999),The human resource architecture: Toward a theory of human capital allocation and development, Academy of Management Review, 24, pp.31-48.

Lopez-Cabrales, A., Vale, R., Herrero, I., (2006), The contribution of core employees to organizational capabilities and efficiency, Human Resource Management, 45,1: pp.81-109. 
Montes, F. J. L., Moreno, A.R., Morales, V. G., (2005), Influence of support leadership and teamwork cohesion on organizational learning, innovation and performance: an empirical examination, Technovation, 25: 1159-1172.

McKelvie, A., Davidsson, P., (2009), From resource base to dynamic capabilities: an investigation of new new firms, British Journal of Management, V.20, pp.63-80.

Morgan, N.A., Douglas, W. Vorhies, C.H.Mason, (2009), Market orientation, Marketing capabilities, and firm performance, Strategic Management Journal, 30,8: pp.909-920.

Newbert, S.L., (2007), Emprical research on the resource-based view of the firm: An assessment and suggestions for future research, Strategic Management Journal, 28; pp.121-146.

Ray, G., Barney, J., Muhanna, W., (2004), Capabilities, business processes, competitive advantage: Choosing the dependent variable in emprical tests of the resource base view, Strategic Management Journal, 25: pp.3-37.

Song, M.C., Benedetto, A., Nason, R.W., (2007), Capabilities and financial performance; The moderating effect of strategic type, J. Of the Acad. Mark. Sci., 35: pp.18-34.

Spanos, Y.E., Prastacos, G., (2004), Understanding organizational capabilities: towards a conceptual framework, Journal of Knowledge Management, 8,3: pp.31-43.

Turner, D. Crowford, M., (1994), Managing current and future competitive performance; the role of competence", in G. Hamel and A. Heene(eds), Competence-based Competition, pp.241-264.

Zahra, S.A., Nielsen, A.P., (2002), Sources of capabilities, integration, and technology commercialization, Strategic Management Journal, 23,5: pp.377-398. 